\title{
Kinetic Analysis of Reversible Inhibition of $16 \alpha$-Hydroxyandrostenedione Aromatization in Human Placental Microsomes by Suicide Substrates of Androstenedione Aromatization
}

\author{
Mitsuteru Numazawa, ${ }^{*}$ Ayako Mutsumi, Mii Tachibana, and Akiko Yoshimura \\ Tohoku Pharmaceutical University; 4-4-1 Komatsushima, Aoba-ku, Sendai 981-8558, Japan. \\ Received December 4, 2002; accepted March 6, 2003
}

\begin{abstract}
To gain insight into the catalytic function of aromatase and its substrate specificity, we studied reversible inhibition of 16 $\alpha$-hydroxyandrostenedione (16 $\alpha$-OHAD) aromatization in human placental microsomes by several suicide substrates of androstenedione (AD) aromatization, including 4-hydroxyAD (1), 6-0xoAD (2) and its 19hydroxy analogue 3 , androst-5-ene-4,7,17-trione (4), and $10 \beta$-acetoxyandrost-5-en-7,17-dione (5) that, in contrast, do not cause a suicide inactivation of $16 \alpha$-OHAD aromatization. All inhibitors examined blocked $16 \alpha$ OHAD aromatization in a competitive manner with apparent $K_{\mathrm{i}}$ values ranging from 0.50 to $980 \mathrm{nM}$. The relative $K_{\mathrm{i}}$ values between inhibitors $1-5$ obtained in the $16 \alpha$-OHAD aromatization experiments were markedly different from those obtained in the AD aromatization experiments. The results predict that all inhibitors examined bind to the 16 $\alpha$-OHAD binding site in a manner that does not cause suicide inactivation of $16 \alpha$-OHAD aromatization. These findings would be useful for understanding the active (binding) site structure as well as the catalytic function of aromatase.
\end{abstract}

Key words human placental aromatase; suicide substrate; binding site; $16 \alpha$-hydroxyandrostenedione aromatization; reversible inhibition

Aromatase is a cytochrome P-450 enzyme responsible for the conversion of androstenedione (AD) and $16 \alpha$-hydroxyandrostenedione (16 $\alpha$-OHAD) into estrogens, estrone, and $16 \alpha$-hydroxyestrone, respectively. ${ }^{1-3)} 16 \alpha$-OHAD rather than $\mathrm{AD}$ is a principal precursor of estrogen production in late pregnancy in the human placenta. ${ }^{4)}$ Inhibitors of aromatase are valuable as therapeutic agents in the treatment of estrogen-dependent breast cancer. ${ }^{5)}$ The human term placenta provides a plentiful source of aromatase for testing inhibitors.

4-Hydroxy $\left.\mathrm{AD}(\mathbf{1})^{6}\right)$ and 6-oxo $\mathrm{AD}(\mathbf{2})^{7}$ are one of the earliest discovered suicide substrates of $\mathrm{AD}$ aromatization in human placental microsomes. Moreover, the 19-hydroxy derivative of inhibitor 2 , compound $3{ }^{8)}$ androst-5-ene-4,7,17trione (4), ${ }^{9)}$ and $10 \beta$-acetoxyestr-5-ene-7,17-dione (5), ${ }^{10)}$ also inactivate $\mathrm{AD}$ aromatization in placental microsomes in a suicide manner (Fig. 1). We recently reported that none of these five suicide substrates cause a time-dependent inactivation of $16 \alpha$-OHAD aromatization in placental microsomes in the presence of NADPH in air. ${ }^{11)}$ In addition, it is known that $16 \alpha$-OHAD is a noncompetitive inhibitor of AD aromatization in placental microsomes. ${ }^{12-14)}$ It was also reported that AD inhibits aromatization of $16 \alpha-\mathrm{OHAD}$ in a noncompetitive manner. ${ }^{14)} \mathrm{AD}$, but not $16 \alpha$-OHAD, protected against the 4-hydroxy steroid 1-mediated suicide inactivation of $16 \alpha$ OHAD aromatization. ${ }^{14)}$

Taken together, it was interesting to determine whether inhibitors $\mathbf{1}-\mathbf{5}$ inhibit $16 \alpha$-OHAD aromatization in a competitive manner or in a noncompetitive manner to understand the nature of the active (binding) site of aromatase. All steroids 1-5 blocked 16 $\alpha$-OHAD aromatization in placental microsomes in a competitive manner.

\section{MATERIALS AND METHODS}

$\left[1 \beta-{ }^{3} \mathrm{H}\right] \mathrm{AD}\left(27.5 \mathrm{Ci} / \mathrm{mmol} ;{ }^{3} \mathrm{H}\right.$-distribution, $\left.1 \beta=74-79 \%\right)$ was purchased from New England Nuclear Corp. (Boston, MA, U.S.A.), and NADPH from Kohjin Co., Ltd. (Tokyo, Japan). $\left[1 \beta-{ }^{3} \mathrm{H}\right] 16 \alpha$-OHAD $(715 \mathrm{mCi} / \mathrm{mmol})$ was microbiologically prepared from commercially available $\left[1 \beta-{ }^{3} \mathrm{H}\right] \mathrm{AD}$ with Streptomyces roseochyomogenes as previously described by us. ${ }^{15)}$ 4-Hydroxy AD (1), 6-oxo AD (2), 19-hydroxy-6-oxo $\mathrm{AD}(3)$, androst-5-ene-4,7,17-trione (4), and $10 \beta$-acetoxyandrost-5-ene-7,17-dione (5) were synthesized according to the previously reported methods. ${ }^{6-10)}$

Preparation of Placental Microsomes Human term placental microsomes (particles sedimenting at $10500 \times \boldsymbol{g}$ for $60 \mathrm{~min}$ ) were obtained as described by Ryan. ${ }^{16)}$ They were washed once with $0.5 \mathrm{~mm}$ dithiothreitol solution, lyophilized, and stored at $-20^{\circ} \mathrm{C}$. No significant loss of aromatase activity occurred over the period of the study ( 2 months).

Aromatase Assay Procedure Aromatase activity was measured according to the procedure of Siiteri and Thompson, ${ }^{17)}$ in which tritiated water released from $\left[1 \beta-{ }^{3} \mathrm{H}\right] \mathrm{AD}$ or $\left[1 \beta-{ }^{3} \mathrm{H}\right] 16 \alpha$-OHAD into the incubation medium during aromatization was used as an index of enzyme activity. All enzymatic studies were carried out in $67 \mathrm{~mm}$ phosphate

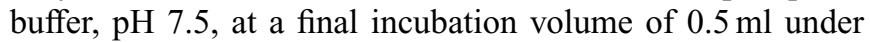
initial velocity conditions. ${ }^{9}{ }^{15)}$ The incubation mixture for the $\mathrm{IC}_{50}$ experiment contained $180 \mu \mathrm{M}$ of NADPH, $300 \mathrm{~nm}$ of $\left[1 \beta-{ }^{3} \mathrm{H}\right] \mathrm{AD}$, or $400 \mathrm{~nm}$ of $\left[1 \beta-{ }^{3} \mathrm{H}\right] 16 \alpha-\mathrm{OHAD}, 20 \mu \mathrm{g}$ protein (for the $\left[1 \beta-{ }^{3} \mathrm{H}\right] \mathrm{AD}$ aromatization experiment) or $40 \mu \mathrm{g}$ protein (for the $\left[1 \beta-{ }^{3} \mathrm{H}\right] 16 \alpha$-OHAD aromatization experiment) of the lyophilized microsomes, various concentrations of steroids $\mathbf{1}-\mathbf{5}$, and $25 \mu \mathrm{l}$ of $\mathrm{MeOH}$, and the entire mixture was incubated at $37^{\circ} \mathrm{C}$ for $20 \mathrm{~min}$ in the experiment with $\left[1 \beta-{ }^{3} \mathrm{H}\right] \mathrm{AD}$ or for $30 \mathrm{~min}$ in the experiment with $[1 \beta-$ $\left.{ }^{3} \mathrm{H}\right] 16 \alpha$-OHAD. For the kinetic assay experiment, the incubation mixture contained $180 \mu \mathrm{M}$ of NADPH, 16,28 , or $34 \mathrm{~nm}$ of $\left[1 \beta-{ }^{3} \mathrm{H}\right] \mathrm{AD}$ or 48,73 , or $105 \mathrm{~nm}$ of $\left[1 \beta-{ }^{3} \mathrm{H}\right] 16 \alpha$-OHAD, $20 \mu \mathrm{g}$ protein (for the $\mathrm{AD}$ aromatization) or $40 \mu \mathrm{g}$ protein (for the 16 $\alpha$-OHAD aromatization) of the microsomes, vari- 
ous concentrations of steroids $\mathbf{1}-\mathbf{5}$, and $25 \mu \mathrm{l}$ of $\mathrm{MeOH}$. The mixture was incubated at $37^{\circ} \mathrm{C}$ for $5 \mathrm{~min}$ in the $\left[1 \beta-{ }^{3} \mathrm{H}\right] \mathrm{AD}$ experiment or for $30 \mathrm{~min}$ in the $\left[1 \beta-{ }^{3} \mathrm{H}\right] 16 \alpha$-OHAD experiment. The rate of $16 \alpha$-OHAD aromatization was about onethird that of $\mathrm{AD}$ aromatization, and thus an increased amount of microsomal protein $(40 \mu \mathrm{g})$ and prolonged incubation time $(30 \mathrm{~min})$ were employed in the experiments with $[1 \beta$ $\left.{ }^{3} \mathrm{H}\right] 16 \alpha$-OHAD. Apparent $K_{\mathrm{i}}$ values were calculated using nonlinear regression analysis with GraFit soft ware. ${ }^{18)}$

\section{RESULTS AND DISCUSSION}

4-Hydroxy AD (1), 6-oxo AD (2) and its 19-hydroxy derivative $\mathbf{3}, 5$-ene-4,7-dione $\mathbf{4}$, and $10 \beta$-acetoxy-5-en-7-one $\mathbf{5}$, which were previously evaluated as suicide substrates of $\mathrm{AD}$ aromatization in human placental microsomes, were tested as reversible inhibitors of $16 \alpha$-OHAD aromatization in this study (Fig. 1). Table 1 summarizes $\mathrm{IC}_{50}$ and apparent $K_{\mathrm{i}}$ values for inhibitors $\mathbf{1}-\mathbf{5}$ obtained by a radiometric assay using $\left[1 \beta-{ }^{3} \mathrm{H}\right] 16 \alpha$-OHAD as a substrate. For comparison, the values were also obtained for $\mathrm{AD}$ aromatization and listed in Table 1 . In the assays, apparent $K_{\mathrm{m}}$ and $V_{\max }$ values for AD or $16 \alpha$-OHAD were $33 \mathrm{~nm}$ and $120 \mathrm{pmol} / \mathrm{min} / \mathrm{mg}$ protein or $580 \mathrm{~nm}$ and $36 \mathrm{pmol} / \mathrm{min} / \mathrm{mg}$ protein, respectively. $\mathrm{IC}_{50}$ values were first obtained and then, to characterize the nature of their binding to the active site of aromatase, aromatization was measured in the presence of several concentrations of inhibitors and the substrate $16 \alpha-\mathrm{OHAD}$ or AD. The results of the studies were plotted on typical Lineweaver-Burk plots. All of the inhibitors examined exhibited clear-cut competitive-type inhibition of $16 \alpha-\mathrm{OHAD}$ aromatization. The results of the assay for powerful to good inhibitors $(1-4)$ are shown in Fig. 2. The apparent inhibition constant $\left(K_{\mathrm{i}}\right)$, an index of the affinity of the enzyme for the inhibitor, was determined by analysis of a Dixon plot in each case.

The $K_{\mathrm{i}}$ values obtained in the $16 \alpha$-OHAD aromatization experiments were fairly low compared with those obtained in the corresponding AD aromatization experiments. This should be due to the fact that the $16 \alpha$-hydroxy substrate $[1 \beta$ $\left.{ }^{3} \mathrm{H}\right] 16 \alpha$-OHAD binds to the active site of aromatase with a lower affinity than the other 16 -deoxy substrate, $\left[1 \beta-{ }^{3} \mathrm{H}\right] \mathrm{AD}$, ( $K_{\mathrm{m}}: 580 \mathrm{~nm}$ for $16 \alpha$-OHAD vs. $33 \mathrm{~nm}$ for AD). The relative $K_{\mathrm{i}}$ values between inhibitors $\mathbf{1}-\mathbf{5}$ (1:12:140:60:1960 for $1: 2: 3: 4: 5)$ in the series of $16 \alpha$-OHAD aromatization experiments were markedly different from those $(1: 1.3: 44.4$ : $20: 666$ for $1: 2: \mathbf{3}: \mathbf{4}: \mathbf{5})$ in another series of experiments with $\mathrm{AD}$ as a substrate. It is noteworthy that the 4-hydroxy steroid $\mathbf{1}$ is an extremely powerful inhibitor of $16 \alpha$-OHAD aromatization. It has previously been reported that in the inhibition study of placental aromatase with 3-deoxy- and 6oxo-steroids, the relative inhibitory activities obtained using $16 \alpha$-OHAD as a substrate are different from those obtained using $\mathrm{AD}$ as a substrate. ${ }^{19)}$

It is now believed that a single enzyme species catalyzes the aromatization independent of the difference in the D-ring substitution of androgens (AD vs. 16 $\alpha$-OHAD). ${ }^{1-3,19)}$ The previous findings ${ }^{12-14,20)}$ have supported the idea of two binding sites for one enzyme in placental microsomes, i.e., one site for $\mathrm{AD}$ aromatization and a second for $16 \alpha-\mathrm{OHAD}$ aromatization. Inhibitors $\mathbf{1}-\mathbf{5}$, which inactivate $\mathrm{AD}$ but not $16 \alpha-\mathrm{OHAD}$ aromatization in a suicide manner, blocked not

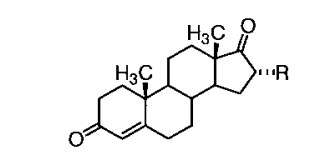

Androstenedione (AD); $\mathrm{R}=\mathrm{H}$ $16 \alpha-$ Hydroxy AD (16a-OHAD); $\mathrm{R}=\mathrm{OH}$

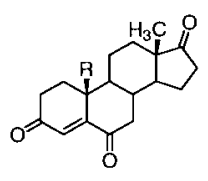

2; $\mathrm{R}=\mathrm{CH}_{3}$
3; $\mathrm{R}=\mathrm{CH}_{2} \mathrm{OH}$

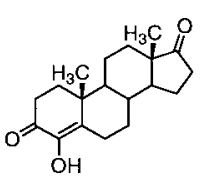

1

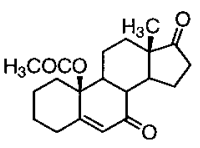

5

Fig. 1. Structures of Aromatase Inhibitors

Table 1. Reversible Inhibition of $16 \alpha$-OHAD Aromatization (Method A) and $\mathrm{AD}$ Aromatization (Method B) by Inhibitors

\begin{tabular}{lcccc}
\hline \hline \multirow{2}{*}{ Inhibitor } & \multicolumn{2}{c}{$\mathrm{IC}_{50}{ }^{a)}(\mathrm{nm})$} & \multicolumn{2}{c}{$K_{\mathrm{i}}^{b)}(\mathrm{nM})$} \\
\cline { 2 - 5 } & Method A & Method B & Method A & Method B \\
\hline 4-OHAD (1) & 0.72 & 180 & 0.50 & 18 \\
6-Oxo AD (2) & 15 & 280 & 6.0 & 24 \\
19-Hydroxy steroid 3 & 165 & 4200 & 70 & 800 \\
4,7-Dione steroid 4 & 60 & $\left.3600^{c}\right)$ & 30 & $\left.430^{c}\right)$ \\
10 $\beta$-Acetoxy steroid 5 & 2800 & $92000^{d)}$ & 980 & $12000^{d)}$ \\
\end{tabular}

a) $400 \mathrm{~nm}$ of $\left[1 \beta-{ }^{3} \mathrm{H}\right] 16 \alpha$-OHAD, $40 \mu \mathrm{g}$ of placental microsomal protein, and 30 min incubation time were used in Method A. $300 \mathrm{~nm}$ of $\left[1 \beta-{ }^{3} \mathrm{H}\right] \mathrm{AD}, 20 \mu \mathrm{g}$ of microsomal protein, and 20-min incubation time were used in Method B. b) Apparent inhibition constant $\left(K_{\mathrm{i}}\right)$ was obtained by Dixon plot. All inhibitors examined showed competitive inhibition of $16 \alpha$-OHAD aromatization (Method A) and AD aromatization (Method B) based on analysis of the Lineweaver-Burk plot. c) Ref. 9. d) Ref. 10.

only AD aromatization but also $16 \alpha$-OHAD aromatization in a competitive manner. Taken together, the results indicate that the suicide inactivators of $\mathrm{AD}$ aromatization would bind to both binding sites but the inactivation reaction, the aromatase-catalyzed production of a reactive electrophile that binds to a nucleophilic residue in the active site of the enzyme, would not occur at the $16 \alpha$-OHAD site. It is known that 6-oxoAD (2) inactivates $\mathrm{AD}$ aromatization in a suicide manner through two subsequent 19-hydroxylations followed by an epoxidation at the $\mathrm{C}-4$ and $\mathrm{C}-5$ positions, producing a 19 -oxo- $4 \beta, 5 \beta$-epoxy intermediate as the reactive electrophile. $^{21,22)}$ In addition, it is speculated that the 19-oxygenated intermediate may play a role as the reactive electrophile in the inactivation of $\mathrm{AD}$ aromatization by 4-hydroxyAD (1) ${ }^{23)}$ Based on those previous findings, it is likely that binding manners of inhibitors 1 and 2 in the $16 \alpha$-OHAD site would not be appropriate for the aromatase-catalyzed 19-oxygenation in each case. Although the mechanisms of the inactivation of $\mathrm{AD}$ aromatization by the inhibitors $3-\mathbf{5}$ are currently unknown, they would also bind to the $16 \alpha$ $\mathrm{OHAD}$ site in a manner not suitable for the inactivation reaction. These findings will be valuable for understanding not only the nature of binding sites of aromatase, especially the 
A

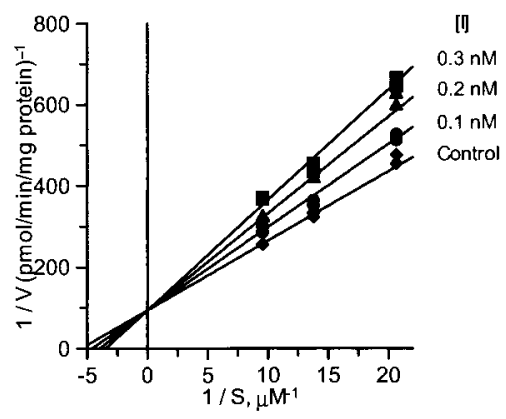

C

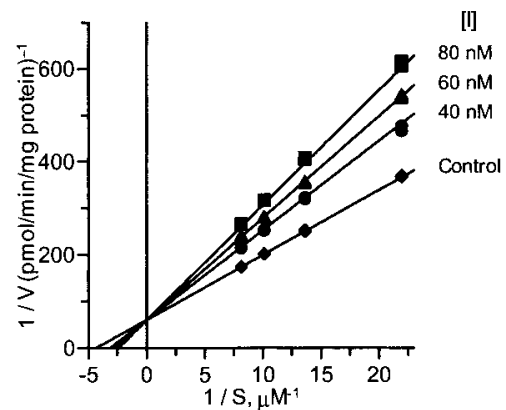

B
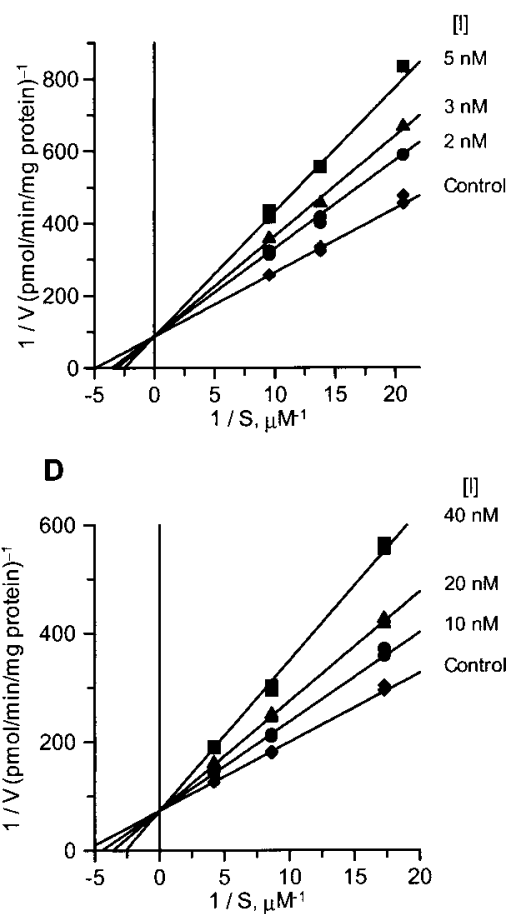

Fig. 2. Lineweaver-Burk Plots of the Inhibition of Human Placental Aromatase by 4-Hydroxy Steroid 1 (A), 6-Oxo Steroid 2 (B), 19-Hydroxy-6-oxo Steroid $3(\mathrm{C})$, and 5-Ene-4,7-dione Steroid 4 (D) with $\left[1 \beta-{ }^{3} \mathrm{H}\right] 16 \alpha-\mathrm{OHAD}$ as a Substrate

Each point represents the mean of two determinations that varied by less than $5 \%$ of the mean. The inhibition experiment with inhibitor 5 gave an essentially similar result to those for $1-4$ (data not shown).

nature of the $16 \alpha$-OHAD site, but also the binding aspects of inhibitors (substrates) in the binding sites.

Acknowledgments This work was supported in part by a Grant-in-Aid for Scientific Research from the Ministry of Education, Science, Sport, and Culture of Japan. We are grateful to Dr. Hideo Imaizumi of the Imaizumi Hospital, Sendai, for generously supplying human term placentas.

\section{REFERENCES}

1) Thompson E. A., Jr., Siiteri P. K., J. Biol. Chem., 249, 5373-5378 (1974).

2) Kellis J. T., Jr., Vickery L. E., J. Biol. Chem., 262, 4413 - 4420 (1987).

3) Yoshida N., Osawa Y., Biochemistry, 30, 3003-3010 (1991).

4) Ryan K. J., "Maternal-Fetal Endocrinology," ed. by Tulchinsky D., Ryan K. J., W. S. Saunders Company, Philadelphia, 1980, pp. 3-6.

5) For example, see Johnson J. O., Crit. Rev. Biochem. Mol. Biol., 33, 375-405 (1998).

6) Brodie A. M. H., Garrett W. M., Hendrickson J. R., Tsai-Morris C. H., Marcotte P. A., Robinson C. H., Steroids, 38, 693-702 (1981).

7) Covey D. F., Hood W. F., Endocrinology, 108, 1597-1599 (1981).

8) Numazawa M., Mutsumi A., Hoshi K., Kigawa M., Oshibe M., J. Steroid Biochem. Mol. Biol., 39, 959-966 (1991).

9) Numazawa M., Tachibana M., Tateda Y., J. Steroid Biochem. Mol.
Biol., 58, 431-438 (1996).

10) Numazawa M., Tachibana M., Steroids, 62, 516-522 (1997).

11) Numazawa M., Tachibana M., Mutsumi A., Yoshimura A., Osawa Y., J. Steroid Biochem. Mol. Biol., 81, 165-172 (2002).

12) Canick J. A., Ryan K. J., Mol. Cell. Endocrinol., 6, 105-115 (1976).

13) Cantineau R., Kremers P., De Graeve J., Gielen J. E., Lambotte R., J. Steroid Biochem., 16, 157-163 (1982)

14) Purohit A., Oakey R. E., J. Steroid Biochem. Mol. Biol., 33, 439-448 (1989).

15) Numazawa M., Mutsumi A., Nakakoshi M., Nagaoka M., Chem. Pharm. Bull., 40, 1839-1842 (1992).

16) Ryan K. J., J. Biol. Chem., 234, 268-272 (1959).

17) Siiteri P. K., Thompson E. A., Jr., J. Steroid Biochem., 6, 317-322 (1975).

18) GraFit version 5.0.3, Erithacus Software Limited, Surrey, UK, 2001.

19) Simpson E., Lauber M., Demeter M., Stirling D., Rodgers R., Means G., Mahendroo M., Kilgore M., Mendelson C., Waterman M., J. Steroid Biochem. Mol. Biol., 40, 45-52 (1991).

20) Numazawa M., Mutsumi A., J. Steroids Biochem. Mol. Biol., 44, 199-201 (1993).

21) Numazawa M., Midzuhashi K., Nagaoka M., Biochem. Pharmacol., 47, 717-726 (1994).

22) Numazawa M., Mutsumi A., Tachibana M., Biochem. Pharmacol., 52, 1253-1259 (1996)

23) Furth P. S., Rosenberger J., Marcotte P. A., Robinson C. H., J. Enzyme Inhibition, 4, 131-135 (1990). 